\title{
Learning in an invertebrate with two types of negative reinforcement
}

JOSEPH E. MORROW ${ }^{1}$

CALIFORNIA STATE COLLEGE AT FULLERTON

Twelve Isopods, Pocellio scaber, were trained to turn opposite a pre-determined preference in a $\mathrm{Y}$ maze to a criterion of eight out of 10 correct turns per day for two consecutive days. Six were reinforced by the application of an aversive stimulus, light, contingent upon a turn towards original preference. Six were reinforced by the withdrawal of the light contingent upon a turn opposite preference. All $S$ s reached the criterion within a range of 30 to 160 trials. There were no statistical differences between the two treatments

The behavior of most vertebrates has been extensively studied under various types of reinforcement. This is not the case with invertebrates, however. Invertebrate studies have generally involved only one type of reinforcement, the application of an aversive stimulus contingent upon some undesired response. With Isopods this has been especially true. Thompson (1957), trained Armadillidium vulgare to turn in a $T$ maze using the application of electric shock for an incorrect response. Bock (1942) trained Porcellio scaber to turn in both $\mathrm{T}$ and $\mathrm{Y}$ mazes by applying a touch with a fine brush when an $S$ turned opposite the desired direction. Harless (1963) trained Porcellio scaber to turn against their original turning preference in a $Y$ maze by presenting an electric light, placed above the maze, when a preference turn was made.

The present study investigated the behavioral effect of another type of reinforcement, the withdrawal of an aversive stimulus contingent upon some desired response. In order to clarify the comparative efficacy of this technique, the application of an aversive stimulus contingent upon an undesired response was also used for the same task.

Method

The Ss of this experiment were 12 Isopods Porcellio scaber gathered in a local garden. They were $3 / 8$ to $5 / 8$ in. in length. Sex and age were not determined.

The maze was a clear glass $Y$ tube with a stem length of $35 \mathrm{~mm}$, arm lengths of $45 \mathrm{~mm}$ and an $8 \mathrm{~mm}$ internal diameter. Placed 6 in. above the choice point of the maze was a model 7100 Tensor brand lamp using a number 93 bulb.

The Ss were randomly divided into two groups of six. Group I was given three days of preference training. Each day consisted of 10 spaced runs through the maze without reinforcement. The direction of each turn was noted and a majority of turns in one direction for an $\mathrm{S}$ was designated as its preference. The next phase of the experiment consisted of training the Ss to turn against their preference. Each $S$ was given 10 spaced trials per day in the maze. When a turn was made, an $\mathrm{S}$ was immediately blocked for 10 sec. by inserting sticks into the maze. At the end of this time the $\mathrm{S}$ was allowed to exit the arm. If the turn was made in the direction of the pre-determined preference, accompanying the blocking was the onset of the electric light for the $10 \mathrm{gec}$. If the turn was opposite preference, the light was not turned on. This procedure was continued until an $\mathrm{S}$ reached a criterion of eight turns opposite preference for two consecutive days.

For Group II preference and training proceeded in the same manner with the following exceptions: During training the lamp was on when an $\mathbf{S}$ was placed in the maze. If a turn was made toward the pre-determined preference, the light was left on. If a turn was made opposite preference, the light was immediately turned off. Group II Ss were also run until a criterion of eight turns opposite preference on two consecutive days was met.

\section{Results and Discussion}

All Ss reached the criterion $(p<.01)$. In Group I where an aversive stimulus was applied for an undesired response the Ss took 50, 80,100,100,120 and 130 trials to reach criterion $(\bar{x}=96.67)$. In Group II where an aversive stimulus was withdrawn for a desired response the Ss took 30, 50,70,90, 90 and 160 trials to reach criterion $(\bar{x}=81.67)$. A $t$ and $U$ test did not indicate any significant differences between the two groups on this variable $(p>.25)$.

These results indicate Porcellio scaber can learn a position response in a $\mathrm{Y}$ maze contingent upon the removal of an aversive stimulus. Further, it would seem that this reinforcement technique is just as effective at controlling behavior in this invertebrate as the application of an aversive stimulus for an undesired response.

This study shows that the behavior of some invertebrates is modified as a function of more than one type of environmental contingency. A full delineation of the possible contingencies is a matter for future research.

\section{References}

Bock, A. Über das Lernvermögen bei. Assellus u Porcellio $Z$. vergl Phyjsiol., 1942, 29, 595-637. (Cited in W. H. Thorpe, Learnand Instinct in Animals. Cambridge, Mass.: Harvard University Press. P 212.)

Harless, M. D. Successive reversals of a position response in the Isopod. Paper read at Washington State Psychological Association, Rosario, Washington, May, 1963.

Thompson, R. Successive reversal of a position habit in an invertebrate. Science, 1957, 126, 163-164.

\section{Note}

1. The assistance of Mrs. Ruth Boyatt is gratefully acknowledged. 